\title{
Synthesis of Silver Nano Particles (Ag-NPs) and their uses for Quantitative Analysis of Vitamin C Tablets
}

\author{
Mamun Ur Rashid ${ }^{1}$, Md. Khairul Hassan Bhuiyan ${ }^{2}$ and M. Emran Quayum ${ }^{1}$ \\ ${ }^{1}$ Department of Chemistry, University of Dhaka, Dhaka-1000, Bangladesh \\ ${ }^{2}$ Department of Physics, Faculty of Agriculture, BAU, Mymensingh, Bangladesh
}

\begin{abstract}
In the present study silver nanoparticles (Ag-NPs) were prepared by using chemical synthesis. Silver nanocolloid solution has been prepared chemically by the reduction of silver salt using sodium borohydride $\left(\mathrm{NaBH}_{4}\right)$ and trisodium citrate $\left(\mathrm{C}_{6} \mathrm{H}_{5} \mathrm{Na}_{3} \mathrm{O}_{7} .2 \mathrm{H}_{2} \mathrm{O}\right)$. Triangular silver nanoplates were also prepared by reducing silver salt using ascorbic acid which is a mild reducing agent. The nanoparticles were characterized by UV-VIS spectrophotometry and Scanning Electron Microscopy (SEM). The reducing character of ascorbic acid was used to determine the amount of ascorbic acid in real sample like vitamin $\mathrm{C}$ tablets that are available in the market of Bangladesh.
\end{abstract}

Key words: Silver nano particles (Ag-NPs), ascorbic acid, reducins agent, SEM, vitamin C

\section{INTRODUCTION}

Over the last decades silver nanoparticles have found applications in catalysis, optics, electronics and other areas due to their unique size-dependent optical, electrical and magnetic properties. $^{1-3}$ Currently most of the applications of silver nanoparticles are in antibacterial/antifungal agents in biotechnology and bioengineering, textile engineering, water treatment, and silver-based consumer products. ${ }^{4-7}$ Samsung has created and marketed a material called Silver nano that includes silver nanoparticles on the surfaces of household appliances. ${ }^{8}$ Silver nanoparticles have been used as the cathode in a silver-oxide battery.

Understanding the reasons of change of the size, shape, surface, and aggregation state of the silver nanoparticles after integration into a target application is critical for optimizing performance. Precisely manufactured monodispersable silver nanoparticles that are free from agglomeration, making them ideal for research, development and use in a variety of innovative applications.

Correspondence to: M. Emran Quayum.

E-mail: relyeq@gmail.com

Dhaka Univ. J. Pharm,. Sci. 12(1): 29-33, 2013 (June)
Aldrich Materials Science offers several silver nanoparticles suspended in a dilute aqueous citrate buffer, which weakly associates with the nanoparticle surface. Silver nanoparticles are being used in numerous technologies and incorporated into a wide array of consumer products that take advantage of their desirable optical, conductive, and antibacterial properties. Silver nanoparticles are used in biosensors and numerous assays where the silver nanoparticle materials can be used as biological tags for quantitative detection. Silver nanoparticles are used to efficiently harvest light and for enhanced optical spectroscopies including metal-enhanced fluorescence (MEF) and surface-enhanced Raman scattering (SERS). Cosmetics and pharmaceutical usages of Silver/Clay nanocomposites were studied by scientists at University Putra, Malaysia. ${ }^{10}$ In the present study, silver nano particles have been synthesized by chemical methods and they were quantitatively used to analyze ascorbic acid in vitamin C tablets.

\section{MATERIALS AND METHODS}

Chemicals: The following chemicals were used without further purification. Potassium chloride $(\mathrm{KCl}$ 
BDH. UK), zinc nitrate $\left(\mathrm{Zn}\left(\mathrm{NO}_{3}\right)_{2} \cdot 6 \mathrm{H}_{2} \mathrm{O}\right.$ MERCK, India), silver nitrate $\left(\mathrm{AgNO}_{3}\right.$, National chemicals, India), copper sulfate $\left(\mathrm{CuSO}_{4} .5 \mathrm{H}_{2} \mathrm{O}, \mathrm{MERCK}\right.$, Germany), absolute ethyl alcohol $\left(\mathrm{CH}_{3} \mathrm{CH}_{2} \mathrm{OH}\right.$, $\mathrm{BDH}, \mathrm{UK}$ ), ethylene glycol (AR, BDH, UK), sodium hydroxide $(\mathrm{NaOH}, \mathrm{BDH}, \mathrm{UK})$, sodium borohydride $\left(\mathrm{NaBH}_{4}, \mathrm{MERCK}\right.$, Germany), ascorbic acid $\left(\mathrm{C}_{6} \mathrm{H}_{8} \mathrm{O}_{6}\right.$ Lobachemie, India), trisodium citrate $\left(\mathrm{C}_{6} \mathrm{H}_{5} \mathrm{Na}_{3} \mathrm{O}_{7} \cdot 2 \mathrm{H}_{2} \mathrm{O}\right.$, MERCK, Germany), ammonia $\left(\mathrm{NH}_{3}\right.$, Active Fine Chemical, Bangladesh), poly vinyl alcohol ( PVA, MERCK, Germany).

Synthesis of Ag nanoparticles using tri sodium citrate (TSC) as a reducing agent. Silver nitrate and trisodium citrate were used as starting materials for the preparation of silver nanoparticles. The silver colloid was prepared by using chemical reduction method. ${ }^{4}$ All solutions of reacting materials were prepared in distilled water. In typical experiment 50 $\mathrm{ml}$ of $0.001 \mathrm{M} \mathrm{AgNO}_{3}$ was heated to boil. To this solution $5 \mathrm{~mL}$ of $1 \%$ trisodium citrate was added drop by drop. During the process, solutions were mixed vigorously and heated until change of color was evident (pale yellow). Then it was removed from the heating device and stirred until cooled to room temperature.

The mechanism of reaction could be expressed as follows ${ }^{11,12}$ :

$4 \mathrm{Ag}^{+}+\mathrm{C}_{6} \mathrm{H}_{5} \mathrm{O}_{7} \mathrm{Na}_{3}+2 \mathrm{H}_{2} \mathrm{O} \rightarrow 4 \mathrm{Ag}^{\mathrm{o}}+\mathrm{C}_{6} \mathrm{H}_{5} \mathrm{O}_{7} \mathrm{H}_{3}+$ $3 \mathrm{Na}^{+}+\mathrm{H}^{+}+\mathrm{O}_{2} \uparrow$

$0.002 \mathrm{M}$ silver nitrate and $0.02 \mathrm{M}$ trisodium citrate were also used in another method. ${ }^{6}$ The colloidal solution of silver nanoparticles were characterize by using UV-Visible spectroscopy and SEM.

Synthesis of Ag nanoparticles using sodium borohydride as a reducing agent. A large excess of $\mathrm{NaBH}_{4}$ was needed to reduce the ionic silver and to stabilize the silver nanoparticles that were formed. Different volumes of $0.001 \mathrm{M}$ silver nitrate were added drop wise (about 1 drop per second) to $30 \mathrm{~mL}$ of $0.002 \mathrm{M}$ sodium borohydride solution that had been chilled in an ice bath. The reaction mixture was stirred vigorously on a magnetic stirrer. The solution turned to light yellow after the addition of $2 \mathrm{~mL}$ of silver nitrate and to brighter yellow when all of the silver nitrate had been added.

$$
\mathrm{AgNO}_{3}+\mathrm{NaBH}_{4} \rightarrow \mathrm{Ag}+\mathrm{H}_{2}+\mathrm{B}_{2} \mathrm{H}_{6}+\mathrm{NaNO}_{3}
$$

The entire addition process took about 3 minutes, after which the stirring was stopped and the stir bar was removed. Reaction conditions including stirring time and relative quantities of reagents (both the absolute number of moles of each reactant as well as their relative molarities) must be carefully controlled to obtain stable yellow colloidal silver. If stirring was continued once all of the silver nitrate was added, aggregation began as the yellow solution first turned to darker yellow then violet and eventually grayish after which the colloid broke down and particle settled out.

Real samples analysis by using AgNPs. A tablet 'Ceevit' (vitamin $\mathrm{C}$ from Square Pharmaceuticals) was weighed, ground to a fine powder. A sample equivalent to approximately 150 mg of ascorbic acid was weighed accurately, transferred into a $100 \mathrm{~mL}$ volumetric flask and diluted upto the mark with water. The mixture was sonicated for $10 \mathrm{~min}$ to aid dissolution and filtered. Then the filtrate was diluted 100 times. From the dilute solution $10 \mathrm{~mL}$ aliquot was transferred into 25 $\mathrm{mL}$ volumetric flask and $100 \mu \mathrm{L}$ of silver seeds, 150 $\mu \mathrm{L}$ of TSC $\left(2.5 \times 10^{-2} \mathrm{M}\right)$ was added to the solution. To this solution, $\mathrm{AgNO}_{3}(0.01 \mathrm{M})$ was added slowly for 5 times, each time $50 \mu \mathrm{L}$ with vigorous stirring. Then, a portion of that solution was transferred within $2 \mathrm{~min}$ into a $1 \mathrm{~cm}$ spectrophotometric cell to record the absorbance. The same procedure was followed for the Nutrivit-C (vitamin $\mathrm{C}$ tablet from ACI pharmaceuticals Ltd).

\section{RUSLTS AND DISCUSSION}

\section{Characterization of Ag NPs colloid solution.} UV-Visible spectroscopy is one of the most widely used techniques for structural characterization of silver nanoparticles. It is quite sensitive to the presence of silver colloids because these nanoparticles exhibit an intense absorption peak due to the surface plasmon excitation. The absorption band in the $350 \mathrm{~nm}$ to $450 \mathrm{~nm}$ region is typical for 
the silver nanoparticles. ${ }^{13}$ With increasing particles size, the plasmon absorption shifts toward red.

The absorbance of colloid solution of $\mathrm{Ag}$ nanoparticles using $10 \mathrm{~mL}$ and $5 \mathrm{~mL}$ of $\mathrm{AgNO}_{3}$ $(0.001 \mathrm{M})$ were observed by the UV-VIS spectrophotometer and the absorbance of the resultant solution were recorded which is shown in the Figure 1.

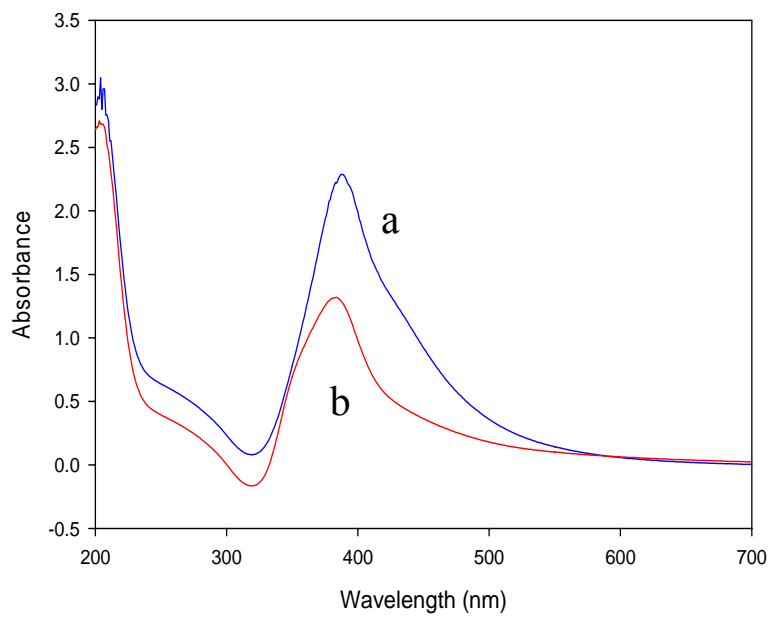

Figure 1. The absorption spectra of Ag NPs using (a) $10 \mathrm{~mL}$ of $\mathrm{AgNO}_{3}$ and (b) $5 \mathrm{~mL} \mathrm{AgNO}_{3}$

The absorption spectra of the colloidal solution of silver are shown in Figure 1 (a) and 1(b). Both the spectra exhibit a plasmon absorption band at $\sim 400$ $\mathrm{nm}$ which is the characteristic of silver nanoparticles. Such plasmon bands are unique physical properties of the nanoparticles themselves. When an external electro-magnetic field such as light is applied to a metal, the conduction electrons move collectively so as to screen the perturbed charge distribution that is known as plasma localized near the metal surface. Using $10 \mathrm{~mL} \mathrm{AgNO}_{3}$ solution to $30 \mathrm{~mL} \mathrm{NaBH}_{4}$ $(0.002 \mathrm{M})$ the absorbance was 2.2860 at the wavelength $390 \mathrm{~nm}$ and using $5 \mathrm{~mL} \mathrm{AgNO}_{3}$ solution to $30 \mathrm{~mL} \mathrm{NaBH} 4(0.002 \mathrm{M})$ the absorbance was 1.3180 at the wavelength $388 \mathrm{~nm}$.

Stability of colloidal solution. The absorbtion spectra of freshly prepared Ag nanocolloids solution and after 1 week of the synthesis of the solution were also recorded and shown in Figure 2.

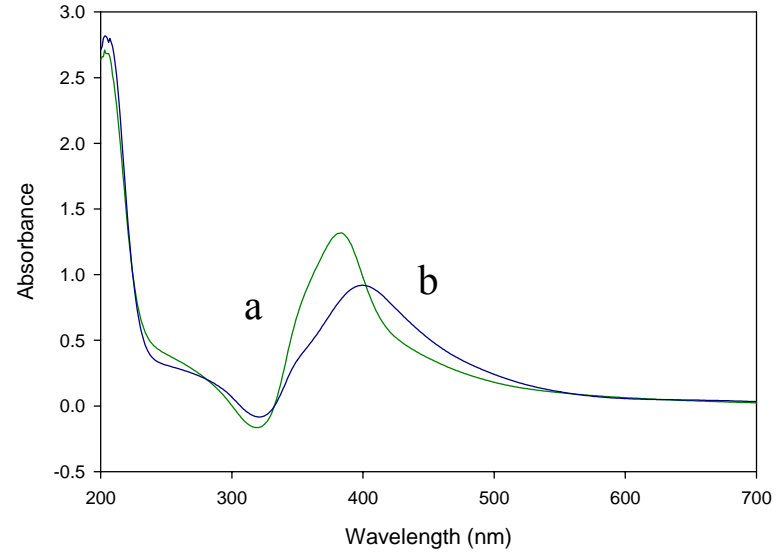

Figure 2. Ag NPs (a) freshly prepared and (b) after 1 week of the synthesis.

The absorbance of freshly prepared $\mathrm{Ag}$ nanocolloid solution using $5 \mathrm{~mL} \mathrm{AgNO}_{3}$ gave an absorbance of 1.3180 at a wavelength of $388 \mathrm{~nm}$. However, after 1 week of the synthesis of the Ag nano colloids, the absorbance spectrum showed a red shift (at around $400 \mathrm{~nm}$ ) with the decrease in the absorbance value. The absorbance was found to be 0.9190. The absorption peak became broader when the spectrum was recorded after 1 week of preparation. This indicated that the Ag nanocolloids aggregated with time.

Synthesis of AgNPs by ascorbic acid. Silver nanoparticles can be prepared by milder reducing agent like ascorbic acid. This is the slower growth process. Reduction of $\mathrm{Ag}^{+}$occurs on silver seeds. The formation of Ag-NPs was confirmed by taking the absorbance of the resultant colloidal solution. So, the absorbance of the silver nanoparticles colloid solution was measured and it is given in Figure 3.

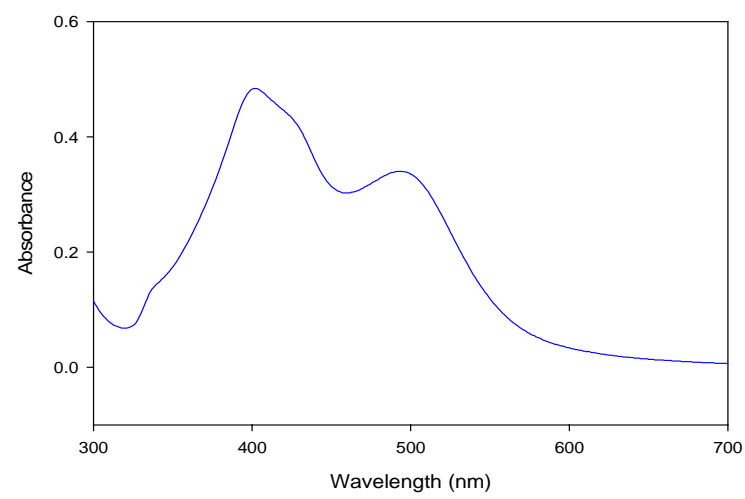

Figure 3. The absorbance spectrum of AgNPs formed by ascorbic acid. 
Figure 3 shows the absorption spectrum of $\mathrm{Ag}$ nanocolloid prepared by ascorbic acid from $\mathrm{AgNO}_{3}$ solution. The spectrum displayed a peak at a wavelength of $402 \mathrm{~nm}$ with an absorbance value 0.4840 . A broad peak was observed at $495 \mathrm{~nm}$ with an absorbance of 0.3400 . The UV-VIS spectrum illustrated three peaks located at approximately 495 $\mathrm{nm}, 402 \mathrm{~nm}$ and $330 \mathrm{~nm}$. These values may correspond to the in-plane dipole resonance, the outof plane dipole resonance and the out-of-plane quadruple for triangular nanoplates respectively. ${ }^{14-17}$

Determination of ascorbic acid. In $25 \mathrm{~mL}$ volumetric flask $100 \mu \mathrm{l}$ of silver seeds, $150 \mu \mathrm{l}$ of TSC $\left(2.5 \times 10^{-2} \mathrm{M}\right)$ and different concentrations of ascorbic acid were added. To this solution, $\mathrm{AgNO}_{3}$ $(0.01 \mathrm{M})$ was added slowly for 5 times $(50 \mu \mathrm{l}$ each time) with vigorous stirring. Then, a portion of that solution was transferred within 2 min into a $1 \mathrm{~cm}$ spectrophotometric cell to record the absorbance. The absorbance of each solution was recorded and compiled in table 1.

Table 1. Absorbance of ascorbic acid solutions

\begin{tabular}{cc}
\hline Concentration $(\mathrm{mM})$ & Absorbance \\
\hline 0.01 & 0.108 \\
0.02 & 0.187 \\
0.03 & 0.297 \\
0.04 & 0.372 \\
0.05 & 0.484 \\
\hline
\end{tabular}

Absorbance spectra for ceevit and nutrivit-C. The absorbance spectra of of Ag nanoparticles in the presence of the ascorbic acid in Ceevit and Nutrivit$\mathrm{C}$ are shown below in Figure 4.

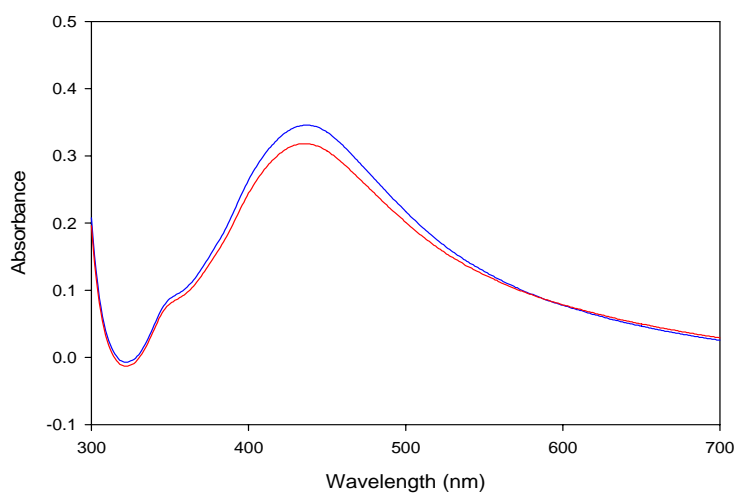

Figure 4. Absorbance spectra of Ag nanoparticles in the presence of Ceevit (upper) and Nutrivit-C (lower).
Figure 4 depicts that the solution containing ascorbic acid from Ceevit shows an absorbance value 0.336 at a wavelength $435 \mathrm{~nm}$ and Nutrivit-C shows an absorbance value 0.319 at a wavelength $432 \mathrm{~nm}$.

Determination of ascorbic acid in vitamin $\mathrm{C}$ tablet in Ceevit and Nutrivit-C. The absorbance value of $\mathrm{Ag}$ nanoparticles in the presence of Ceevit and Nutrivit-C is plotted on the calibration curve of $\mathrm{Ag}$ nanoparticles in the presence of different amount ascorbic acid containing solution to determine the concentration of the ascorbic acid present in the solution as shown in Figure 5.

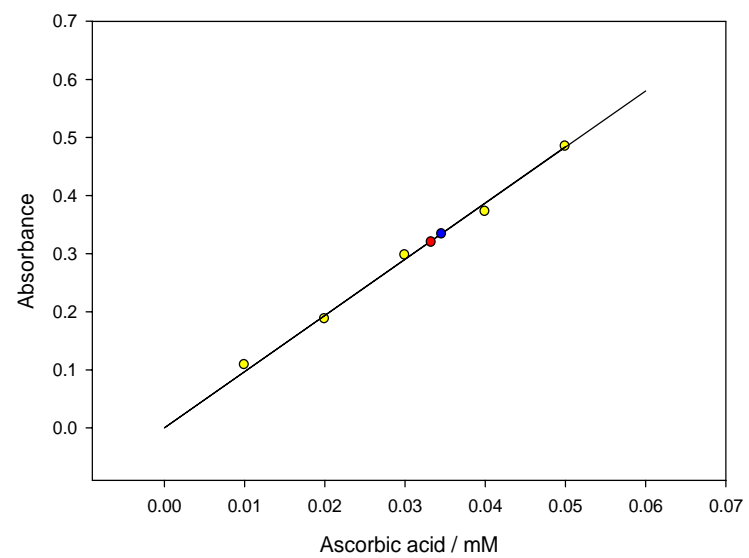

Figure 5. Absorbance of Ag NPs in the presence of ascorbic acid vs concentration of ascorbic acid.

Figure 5 shows the calibration curve, from which the concentration of ascorbic acid present in Ceevit solution was found to be $0.0346 \mathrm{mM}$ and for Nutrivit-C, the concentration was $0.0335 \mathrm{mM}$. The same procedure was followed for 2 times for both of the samples and the observed values are shown in the following table (Table 2.)

Table 2. Quantitative results of ascorbic acid in tablet samples

\begin{tabular}{ccc}
\hline \multirow{2}{*}{ Samples } & \multicolumn{2}{c}{ Acsorbic acid found (mg per tablet) } \\
\cline { 2 - 3 } & Claimed & Proposed Method \\
\hline \multirow{3}{*}{ Ceevit } & 250 & 248.05 \\
& 250 & 253.91 \\
& 250 & 256.85 \\
Nutrivit-C & 250 & 242.90 \\
& 250 & 245.85 \\
& 250 & 248.05 \\
\hline
\end{tabular}




\section{CONCLUSION}

In the present study, silver nanoparticles and silver nanocolloid solution were prepared chemically by the reduction of silver salt. The nano species were characterized by UV-VIS spectrophotometry and SEM. The prepared silver nanomaterials were used to determine the amount of ascorbic acid present in real sample like vitamin $\mathrm{C}$ tablets (Ceevit and Nutrivit-C) that are available in the market of Bangladesh. The results obtained by the proposed method were in good agreement with that of the claimed values of ascorbic acid by the pharmaceutical companies.

\section{REFERENCES}

1. Turner, T. 1908. Transparent Silver and Other Metallic Films. Proc. Roy. Soc. Lond. A 81 (548): 301. Bibcode 1908RSPSA.81.301T. JSTOR 93060.

2. Fahlman, B.D. 2007. Materials Chemistry. Springer Pubications 282-283. ISBN 1402061196.

3. Anisa, M., Abdallah, S.D. and Singer, P.A. 2003. 'Mind the gap': science and ethics in nanotechnology. Nanotechnology 14, R9-R13 doi:10.1088/0957-4484/14/3/ 201.

4. Li, W.R., Xie, X.B., Shi, Q.S., Zeng, H.Y., Ou-Yang, Y.S., Chen, Y.B. 2010. Antibacterial activity and mechanism of silver nano particles on Escherichia coli. Appl Microbiol Biotechnol. 85, 1115-22.

5. Lubick, N. 2008. Nano silver toxicity: ions, nanoparticles. Environ. Sci. Technol. 42, 8617.

6. Sajjad, S. and Nasseri, A. 2011. Synthesis and stabilization of $\mathrm{Ag}$ nanoparticles on a polyamide surface and its antibacterial effects. Int. Nano. Lett. 1, 22.

7. Prakash, N.B., Nivedita, S and Subrata, R. 2011. Use of sericin of Bombyx mori in the synthesis of silver nanoparticles, their characterization and application. Indian $J$. Fibre Textile Res. 36, 168-171.
8. Mansoor, B.A., Kamyar, S., Majid, D., Wan, M.Z., Wan Y. and Nor A.I. 2009. Synthesis and characterization of silver/clay nanocomposites by chemical reduction method. American J. Appl. Sci. 6, 1909.

9. David, D., Evanoff, Jr. and George, C. 2005. Synthesis and optical properties of silver nanoparticles and arrays. Chem. Phys. Chem. 6, 1221-1231.

10. Yuning, Li., Yiliang W. and Beng S.O. 2005. Facile synthesis of silver nanoparticles useful for fabrication of high-conductivity elements for printed electronics. J. Am. Chem. Soc. 127, 3266-3267.

11. Silva, E. I., Rivas, J., Leon, L.M., Isidro, M.A. and Lopez, Q. 2007. Synthesis of silver-coated magnetite nanoparticles. J. Non-Crystalline Solids 353, 829-831.

12. Hangxun, $\mathrm{Xu}$ and Kenneth, S.S. 2010. Water-soluble fluorescent silver nanoclusters. Adv. Mater. 22, 1078-1082.

13. Kadir, A., Joseph, R., Lakowiez and Geddes C.D. 2005. Rapid deposition of triangular silver nanoplates on planar surfaces: application to metal-enhanced fluorescence. $J$. Phys. Chem. B. 109, 6247-6251.

14. Junwei, Z., Xiaowei, L., Renao, G. and Tianhong, L. 2002. Comparison of the surface properties of the assembled silver nanoparticle electrode and roughened silver electrode. $J$. Phys. Chem. B. 106, 1019-1023.

15. Peter, L., Redmond, A., Hallock, J. and Louis, E.B. 2005. Electrochemical Ostwald ripening of colloidal Ag particles on conductive substrates. Nano Letters. 5, 131-135.

16. Tsung-Hsuan, T., Soundappan T. and Shen-Ming, C. 2010. Green synthesis of silver nanoparticles using ionic liquid and application for the detection of dissolved oxygen. Electroanalysis 22, 680-687.

17. Chien, C.W., Marta, O., Luconi, A. Masi, N. and Liliana, P.F. 2009. Derivatized silver nanoparticles as sensor for ultra-trace nitrate determination based on light scattering phenomenon.Talanta 77, 1238-1243. 